\title{
Bilateral Simultaneous Testicular Torsion in a 17-Year-Old Boy: Case Report and Review of Literature
}

\section{K Fathi and F Harangi*}

Department of Pediatrics, Balassa Janos County Hospital, Szekszard, Hungary

*Corresponding Author: K Fathi, Consultant Pediatric Surgeon, Department of Pediatrics, Balassa Janos County Hospital, Szekszard, Hungary.

Received: August 08, 2019; Published: September 13, 2019

DOI: 10.31080/ASPE.2019.02.0147

\begin{abstract}
Bilateral testicular torsion in adolescent is a rare condition, it is more frequent in neonate. Herein we describe a case of 17-yearold boy presented with sudden onset of left testicular pain of 1-hour duration. Left testicular torsion was diagnosed by physical examination and confirmed by testicular Doppler ultrasound. Right testis was asymptomatic with normal Doppler ultrasound findings. Surgical exploration of both testes showed salvageable left testicular torsion and torsion of right testis. Bilateral untwisting and orchidopexy performed. Although the occurrence of bilateral testicular torsion in adolescence is rare, as this case demonstrates, it can happen simultaneously without initial symptoms. Therefore, bilateral scrotal exploration and orchidopexy is mandatory in unilateral testicular torsion.

Keywords: Bilateral Testicular Torsion; Synchronous; Spermatic Cord; Adolescent
\end{abstract}

\section{Introduction}

Testicular torsion is an acute vascular event in which the testis is twisted around its spermatic cord causing ischemia to the testis. It is most common genitourinary tract emergency in children requiring urgent surgery. Bilateral testicular torsion is more common in neonates, however, in adolescent it occurs rarely, only five cases have been reported in the literature [1].

\section{Case Report}

A 17-year-old boy presented with 1-hour history of severe left hemi-scrotal pain, radiating to left groin and nausea. The pain started during sleep and he did not have any sport injury or trauma. Physical examination revealed pale patient, left testicle was positioned higher than the right side, lying obliquely, extremely tender and mildly enlarged. The right testicle was of normal size and non-tender. There was negative cremasteric reflex on the left side (Figure 1). Emergency Doppler ultrasound scan showed no intratesticular colour flow (circulation) in the left testicle. The left epididymis was grossly thickened with moderate left scrotal hydrocele. Colour flow was seen in right testicle and epididymis. Emergency left hemi-scrotum exploration showed dusky left testicle with $720^{\circ}$ clockwise torsion of the spermatic cord. Following untwisting of testis, its circulation improved and recovered (Figure 2). Then the right hemi-scrotal exploration was performed, which revealed $180^{\circ}$ clockwise torsion with normal coloured testicle (Figure 3). The testis was untwisted and bilateral orchidopexy performed. Ten months following bilateral orchidopexy, Doppler ultrasound examination showed that both testicles are of normal, equal volume and normal circulation and echogenicity (Figure 4).

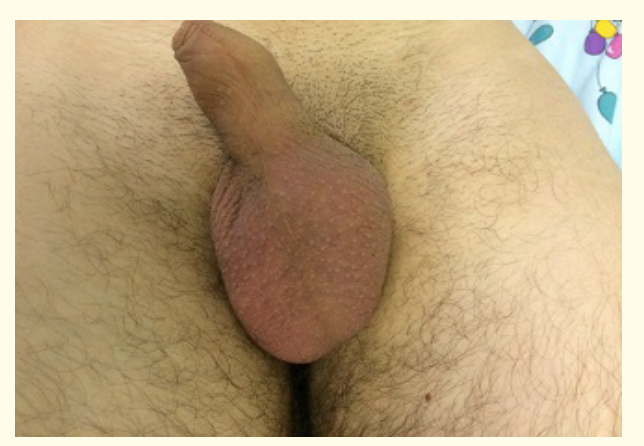

Figure 1: Left testis is located higher due to torsion. 


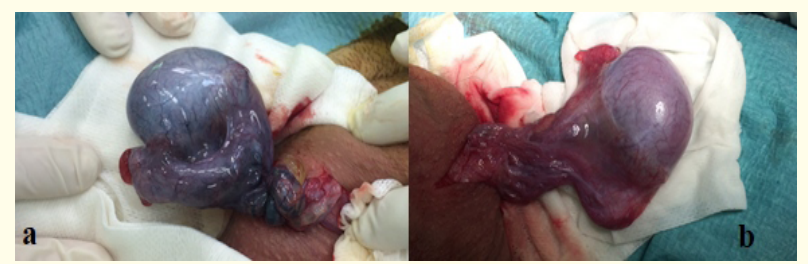

Figure 2: a. Left testis with $720^{\circ}$ torsion. b. after untwisting, left testis circulation and coloration recovered.



Figure 3: In asymptomatic right testis $180^{\circ}$ twist was noted.



Figure 4: Doppler ultrasound of left and right testicle 10 months post-torsion, normal circulation noted.

\section{Discussion}

Bilateral simultaneous testicular torsion in adolescent is very rare, only five cases have been reported in the literature [2-6]. It is more common in neonates, synchronous bilateral neonatal testicular torsion counts for $11-21 \%$ of all reported neonatal testicular torsions [7-12]. There are two types of testicular torsion, namely extravaginal torsion occurs in neonates, and intravaginal torsion particularly seen in adolescent with the peak incidence of 14 years of age [13]. The etiology of extravaginal torsion is due to flimsy or lack of attachment of tunica vaginalis to the scrotal wall, which allows free movement of testis around spermatic cord commonly seen in neonates. This also suggest the higher incidence of bilateral testicular torsion in neonatal age [2]. Intravaginal torsion on the other hand, occurs in adolescent due to loose attachment of tunica vaginalis to the testis (tunica albuginea). This is called "bell clapper" deformity, an arrangement that leaves free space between the testis and tunica vaginalis, where the testicle hanging like the clapper of bell and can rotate freely around the spermatic cord within the tunica vaginalis [3].

Testicular pain is the primary symptom of testicular torsion, occurring in $80 \%$ of patients. Testicular torsion can happen at any time, while standing, sleeping, exercising, or sitting with abrupt onset and shorter duration of symptoms compared to torsion of appendix testes. Sixty nine percent of cases present within 12 hours of onset of torsion [14]. The testis lies higher, with oblique or transverse position and absence of cremasteric reflex [15]. Accompanying gastrointestinal and abdominal symptoms such as nausea, vomiting, lower quadrant abdominal pain have been noted. Occasionally patients with right lower quadrant abdominal pain referred with suspected appendicitis, turned out to have an acute right testicular torsion. Therefore testicular examination of all boys presenting with lower quadrant abdominal pain should be part of physical examination, in order to avoid missed testicular torsion. Doppler ultrasound scan is a good diagnostic tool, permits any vascular and echogenicity changes of the testis, with sensitivity of $63.6-100 \%$ and specificity of $97-100 \%$ [16]. However early on the testicular torsion might not show any ultrasonographical changes. As in our case, the right testis was asymptomatic and Doppler ultrasound showed normal vascularity of the testis. This case demonstrates that initial scrotal examination and Doppler ultrasound scan are unreliable tolls and can be misleading in the diagnosis of bilateral synchronous testicular torsion. The time elapsed from the onset of symptoms until the exploration and the degree of cord twisting are the most crucial factor in the degree of damage to the testicle. Some authors reported severely damaged, non-salvageable testicles after 24 hours of duration and more than $360^{\circ}$ of twist [17-19]. Therefore, when testicular torsion is suspected, there should be least delay in diagnostic work-up as the time is tickling and further delay increases ischemic and irreversible damage to the testicle. Manual detorsion of the testis by outwards rotation of the testis under Doppler ultrasound guidance should be done to relief pain and improve testicular circulation followed by urgent bilateral orchidopexy [20].

\section{Conclusion}

Bilateral testicular torsion is extremely rare, mostly seen in neonates, but may also occur in adolescents or adults. Emergency bilateral hemi-scrotal exploration is mandatory in patients presenting with acute unilateral scrotal pain, to avoid missing contralateral asymptomatic testicular torsion. 


\section{Bibliography}

1. Lorenzo l, Martinez-Cuenca E, Broseta E. Bilateral testicular torsion in an adolescent: a case with challenging diagnosis. Int Braz J Urol. 2018 44:393-396

2. Cohen S, Gans W, Slaughenhoupt B. Acute scrotum, American Urological Association Guidelines.2016. available at. < https://www.auanet.org/education/acute-scrotum.cfm>.

3. Osada Y, Tanada T, Ishisawa N. Simultaneous bilateral testicular torsion in the adolescent. Urol Int. 1985 40:179-180

4. Benge BN, Eure GR, Winslow BH. Acute bilateral testicular torsion in the adolescent. J Urol. 1992 148:134-134

5. Beliaev AM, Mundy I. Bilateral simultaneous testicular torsion presenting as a diagnostic dilemma. BMJ Case Rep. (2013).

6. Vadhwana B, Manson-Bahr D, Godbole H. A rare case: spontaneous bilateral synchronous testicular torsion. Int Urol Nephrol. 2015 47:1519-1520

7. Abbas T.O, Ali M. Bilateral neonatal testicular torsion hidden surgical nightmare. Front. Pediatr., 20 November 2018, < https://doi.org/10.3389/fped.2018.00318>.

8. Barca PR, Dargallo T, Jardon JA, Estevez E, Bautista A, Varela Cives R. Bilateral testicular torsion in the neonatal period. J Urol. (1997) 158:1957-9. 10

9. Burge DM. Neonatal testicular torsion and infarction: aetiology and management. Br J Urol. (1987) 59:70-3

10. LaQuaglia MP, Bauer SB, Eraklis A, Feins N, Mandell J. Bilateral neonatal torsion. J Urol. (1987) 138:1051-4

11. Baglaj M, Carachi R. Neonatal bilateral testicular torsion: a plea for emergency exploration. J Urol. (2007) 177:2296-9

12. Yerkes, E.B., et al. Management of perinatal torsion: today, tomorrow or never? J Urol, 2005. 174: 1579. http://www. ncbi.nlm.nih.gov/pubmed/16148656

13. Williamson RCN: Torsion of the testis and allied conditions. Br J Surg 1976 63:465-676

14. Makela, E., et al. A 19-year review of paediatric patients with acute scrotum. Scand J Surg, 2007. 96: 62. http://www.ncbi. nlm.nih.gov/pubmed/17461315
15. Kadish, H.A., et al. A retrospective review of pediatric patients with epididymitis, testicular torsion, and torsion of testicular appendages. Pediatrics, 1998. 102: 73. http:// www.ncbi.nlm.nih.gov/pubmed/9651416

16. Baker, L.A., et al. An analysis of clinical outcomes using color doppler testicular ultrasound for testicular torsion. Pediatrics, 2000. 105: 604. http://www.ncbi.nlm.nih.gov/ pubmed/10699116

17. Wright JE. Torsion of the testis. Br J Surg. 1977 64:274-276

18. Martin AD, Rushton HG. The prevalence of bell clapper anomaly in the solitary testis in cases of prior perinatal torsion. J Urol. 2014 191(5 suppl):1573-1577

19. Visser, A.J., et al. Testicular function after torsion of the spermatic cord. BJU Int, 2003. 92: 200. http://www.ncbi.nlm.nih. gov/pubmed/12887467

20. Cornel, E.B., et al. Manual derotation of the twisted spermatic cord. BJU Int, 1999. 83: 672. http://www.ncbi.nlm.nih. gov/pubmed/10233577

Volume 2 Issue 10 October 2019

(C) All rights are reserved by $\mathrm{K}$ Fathi and F Harangi. 